This item was submitted to Loughborough's Research Repository by the author.

Items in Figshare are protected by copyright, with all rights reserved, unless otherwise indicated.

\title{
Women's fear of crime and preference for formidable mates: how specific are the underlying psychological mechanisms?
}

PLEASE CITE THE PUBLISHED VERSION

https://doi.org/10.1016/j.evolhumbehav.2016.01.005

\section{PUBLISHER}

(C) Elsevier

VERSION

AM (Accepted Manuscript)

\section{PUBLISHER STATEMENT}

This work is made available according to the conditions of the Creative Commons Attribution-NonCommercialNoDerivatives 4.0 International (CC BY-NC-ND 4.0) licence. Full details of this licence are available at: https://creativecommons.org/licenses/by-nc-nd/4.0/

\section{LICENCE}

CC BY-NC-ND 4.0

\section{REPOSITORY RECORD}

Ryder, Hannah L., John Maltby, Lovedeep Rai, Phil Jones, and Heather D. Flowe. 2019. "Women's Fear of Crime and Preference for Formidable Mates: How Specific Are the Underlying Psychological Mechanisms?". figshare. https://hdl.handle.net/2134/20943. 
Hannah Ryder ${ }^{1}$, John Maltby ${ }^{1}$, Lovedeep Rai ${ }^{1}$, Phil Jones ${ }^{2}$, and Heather D. Flowe ${ }^{3}$ 
Previous research shows that feelings of vulnerability, as measured by fear of crime, are associated with preferences for physically formidable and dominant mates (PPFDM), ostensibly because of the physical protection such mates can afford. In the lab and in the field, we tested whether the relationship between PPFDM and fear of crime is pronounced when the risk of crime is relatively high, and for crimes that are evolutionarily more costly. In Study 1, women were presented with daytime and night time images that featured a lone shadowy male figure, crime hotspots and safespots, and they reported their risk of victimisation in the situation depicted in the image. In Study 2 , we had female participants walk through crime hotspots and safespots in a city centre during the daytime, and had them report their perceived victimisation risk for different types of crime, perpetrated by a male- versus female. Participants in Study 1 and 2 also completed a scale that measures PPFDM. In both studies, we found that PPFDM was positively associated with fear of crime in hotspots and in safespots. Additionally, fear of crime was significantly affected by risk situation (i.e., safespot versus hotspot, night time versus daytime). The relationship between PPFDM and fear, however, did not vary in relation to risk situation, perpetrator gender, or crime type, suggesting that the psychological mechanisms underlying the relationship between perceived risk of victimisation and PPFDM are general in nature. Women who prefer physically formidable and dominant mates tend to feel more at risk of crime, regardless of the situational risk factors present. Key words: hypothesis, rape avoidance 

Women's Vulnerability and Preferences for Physically Formidable and Dominant Mates: How Specific Are the Underlying Psychological Mechanisms? Natural selection increases the prevalence of adaptive traits that benefit successful reproduction and survival (Dobzhansky, 1956). Crime and violence, particularly sexual assault, can reduce significantly a female's fitness as well as her relatives' and close allies' fitness (e.g., see Duntley \& Shackelford, 2012). Criminal victimisation has multiple costs (Perilloux et al. 2012), including physical and psychological pain (Thornhill \& Palmer, 2000), such as depression (Atkeson et al. 1982), untimely pregnancy with an undesired mate (Gottschall \& Gottschall, 2003), or death (Duntley \& Shackelford, 2012), resulting in additional costs such as loss of future reproduction and harm to existing offspring. As such, evolutionary theorists (e.g., Duntley \& Shackelford, 2012; Smuts, 1992) have argued that violence during our ancestral history has contributed to shaping the psychology of women through the production of adaptations that are designed to reduce victimisation costs.

Duntley and Shackelford (2012) argue that, whilst avoidance of violence is the most effective strategy, an attack may not always be unavoidable, and thus individuals often must resort to alternative strategies for protection. They hypothesise that people have evolved adaptations to reduce their risk of victimisation. For example, women's mate selection criteria should, and indeed, evidence suggests that it does, include a preference for mates who can offer protection for themselves and their offspring (e.g., Buss, 1994; Snyder et al. 2011) through being physically formidable and dominant, known as "the bodyguard hypothesis" (Wilson \& Mesnick, 1997). For example, women prefer protective qualities in male friends (Bleske-Rechek \& Buss, 2001) and shortterm or extra-pair mating partners (Buss \& Schmitt, 1993; Greiling \& Buss, 2000), supposedly due to the protection they can afford.

However, men who have these protective qualities also have less desirable traits that are costly to their mates. Traits that enable protection, such as aggression, dominance and physical 
formidability, can also be costly to partners (Snyder et al. 2011). For example, aggressive traits (e.g., anti-sociability and anger) predict partner abuse (Lorber \& O'Leary, 2004) and have been associated with coercion (e.g., Hawley, 2003). Coercion, as well as increased anger, physical aggression, and involvement in fights are also more prevalent in men who are physically stronger than average (Archer \& Thanzami, 2009; Sell et al. 2009). Moreover, high testosterone in men is associated with lower sympathy and decreased response to infant cries (Fleming et al. 2002). Despite these costs, some women still desire men with traits associated with aggressive-formidability. Snyder et al. posit that women's long-term mate preferences are the product of evolved psychological mechanisms, wherein women who feel vulnerable to violence select mates with traits indicative of aggressive dominance and physical formidability. They maintain that preferences for physically formidable and dominant males (PPFDM) adapt to women's circumstances, and may fluctuate as the need for protection varies. Furthermore, women base their perceptions of how at risk they are on the prevalence of violence in their environment, and on their ability to defend against it, whether on their own, or via protection afforded by others. Optimally, women's mate preferences would be periodically updated in keeping with environmental circumstances. Based on this theoretical framework, Snyder and colleagues hypothesised that women's vulnerability to violent crime would predict PPFDM, particularly in relation to long-term partner preferences. Put differently, the relationship between vulnerability and PPFDM is strongest when the benefits of formidable mates, such as increased access to resources and protection, outweigh the costs. To investigate the relationship between fear of crime and mate preferences, Snyder et al. (2011) measured women's PPFDM as well as their subjective perceived vulnerability to crime, asking them how worried they were about becoming a victim of various types of crime (mugging, violent attack, sexual assault, burglary, vehicle damage/vandalism, theft of personal property, motor vehicle theft, and general vandalism), using the British Fear of Local Crime Survey. They also estimated, based on zip code, women's actual risk of crime (i.e., based on property and violent crime levels combined) in their present environment and childhood environment, as well as median household 
income and income inequality. They found that PPFDM was related to subjective perceptions of crime (Studies 1 and 2), as well as actual childhood levels of violence (but only in Study 1).

Preferences were not related to current actual levels of crime, to current income, or to current or childhood income inequality. In Study 3, they sought to prime women's fear of crime, randomly assigning women to view photographs that portrayed either danger or safety cues. They tested whether women who had been exposed to dangerous cues would show heightened levels of fear of crime, and stronger preferences for formidable mates. However, the priming manipulation did not affect fear of crime or mate preferences. Rather, fear of crime predicted muscularity preferences, and subjective fear of crime predicted preferences for formidable mates.

Based on these findings, Snyder et al. suggested that PPFDM is dependent on a woman's self-assessed vulnerability, rather than on actual prevailing rates of violence. They also proposed that perceived vulnerability may be a relatively stable trait that is not sensitive to state perturbation, but rather that is acquired in childhood via exposure to violence. Life history models of attachment posit that early infancy provides crucial information about environmental risks (e.g., Del Giudice, 2009). Evidence supports this proposition. Sherman et al. (2015) found that the prevalence of registered sex offenders in people's childhood neighborhood was associated with their perceptions of their own criminal victimisation risks as adults. What is more, future reproductive strategies might be based on childhood exposure to crime. However, it is only adaptive to base future reproductive strategies on childhood indicators of risk in relatively stable environments (Del Giudice, 2009). Marzoli and colleagues (2013) found current environmental factors, such as prevalence of violence, to directly influence mate preferences, such as preferences for dominance in a male partner. Therefore, the association between PPFDM and fear of crime may vary according to the likelihood and evolutionary costs of violence.

Another explanation for the lack of correlation between current residential area and PPFDM found by Snyder et al. may be due to the possibility that women with high PPFDM generally feel more vulnerable regardless of where they currently live. Therefore, we will extend Snyder and 
colleagues' (2011) research by measuring women's current PPFDM levels and assessing whether women with relatively higher PPFDM feel higher risk of criminal victimisation compared to women with lower PPFDM in response to cues of crime. We assess whether the impact of crime cues on women's fear of crime are predicted by PPFDM. In particular, we studied whether PPFDM is associated with risk perceptions only when victimization risk is relatively high, and only for crimes that are evolutionarily more costly (i.e., male-perpetrated crime, especially rape). If PPFDM and risk perceptions correspond only when risk is high, this would suggest that women with relatively strong PPFDM are more sensitive to crime cues. On the other hand, if PPFDM and risk perceptions are associated even when women are not at risk of crime, and for all types of crime, even femaleperpetrated crime, this would suggest the psychological mechanisms underlying PPFDM and risk perceptions are more general in nature, with women who prefer more physically dominant and formidable mates tending to feel more vulnerable no matter what their circumstances.

To investigate, in Study 1, we presented women with images taken from a city centre that varied in relation to natural cues (e.g., alleyways, deserted backstreets, broken windows, a shadowy figure of a man) indicative of crime (see Jones et al. 2011). Additionally, the images were taken during the day and at night. Women evaluated their risk of a violent victimization in the situation depicted in the image. We relied on these natural cues to elicit subjective feelings of being at risk of crime (see Abdullah et al. 2015; de Leon \& Cohen, 2005; Jones et al. 2011). Rape is stereotypically associated with strange males and alleyways (e.g., McKibbin et al. 2009), and the risk of violent crime is higher at night compared to during the day (Office for National Statistics, 2013). Thus, women should feel particularly at risk of victimization in response to the images depicting these natural crime cues. Additionally, recent evidence suggests that there is a strong link between fear of crime and the prevailing crime rate within a 1.0 mile radius of people's home address (Zhoa, Lawton, \& Longmire, 2015). This suggests that crime cues in one's immediate environment impact on one's perceived risk of victimization. Therefore, in Study 2, we had women walk through a city centre, following a route that varied with respect to natural crime cues, and they indicated at several points 
142 along the route their risk of victimization for different types of crimes (rape, robbery, and assault), committed by a male versus female assailant.

If women with stronger PPFDM are more sensitive to threats in their environment, then PPFDM and risk perceptions should correspond when women are at the most risk of crime. Therefore, PPFDM should predict risk only when there is a shadowy male figure present and when there are cues indicative of crime present in the environment, and not when these cues are absent (Hypothesis 1), and at night time compared to the daytime (Hypothesis 2). Additionally, we also explored whether different types of crime distinctly impact women in relation to their PPDFM. Therefore, PPFDM and crime type should interact, showing that the relationship between PPFDM and risk is larger for sexual assault than for physical assault and robbery, because sexual assault poses a larger potential evolutionary cost (Hypothesis 3). What is more, the Shadow of Sexual Assault Hypothesis (Ferraro, 1995; 1996; Warr, 1985) posits that women show a heightened fear of crime in comparison to men because all crimes, in particular male-perpetrated crimes, can escalate into sexual crimes. Therefore, PPFDM and perpetrator gender should have an interactive effect on risk perceptions, such that PPFDM corresponds with risk perceptions only for male- as opposed to female-perpetrated crime (Hypothesis 4).

Method

Participants participated via an online study in return for monetary compensation. The majority of women reported being White (70.3\%), whilst other ethnicities were reported as South Asian (15.8\%), East Asian (6.3\%), Black (3.2\%), Hispanic (1.3\%), Latino (.6\%) or other (2.5\%). The online survey was designed to screen out men. 


\section{Materials and procedure}

The study was conducted online with Mechanical Turk participants. At the recruitment stage, participants were told that the study entailed evaluating images and that they had to complete the study on their own. Participants first provided demographic information (i.e., age, gender, relationship status, ethnicity, residential country). Participants who indicated they were a woman were automatically directed to the online experiment. The study concluded after the demographic survey for participants who indicated they were a man. We did not tell participants at any stage that we were interested in recruiting only women. This was to increase the validity of participants' self-reports with respect to gender. Since the study was conducted online, we were not in a position to verify participant gender. Attention filter questions were included; none of the participants failed these checks. Participants were remunerated $\$ 1.50$ for their participation.

The experiment entailed the participant rating a series of images, which were presented in a random order. Across the images, crime risk (crime safespot, crime hotspot, versus shadowy male) and time of day (daytime versus night time) were varied within subjects. To vary these factors, the images were taken at various locations around a city centre. For the safespots, there were 13 images, all comprised of open spaces. For the crime hotspots, there were 25 images in total, including 11 images of alleyways, and 14 of backstreets, and for the shadowy male figure, there were 11 images. Each location was photographed both during the daytime and the night time. Participants viewed each image for three seconds, after which they were asked to rate their risk of a violent victimization at that particular location if they were there on their own, on an 11 point scale that was anchored from $0 \%$ (not at all at risk) to $100 \%$ (absolutely at risk). Participants also completed the preference for formidable mates scale (see Snyder et al. 2011), which assessed participants' preferences for long term partners who were: dominant, domineering, commanding, over-bearing, tough-guy, bad-boy, strong, powerful, broad shoulders, tall, could win a fight if necessary. Women rated these traits on a scale of 1 (not at all important) to 9 (extremely 
important). The order in which participants completed the image rating task and formidable mates scale was counterbalanced across participants. The study took 15 minutes to complete.

\section{Measures and Data Analysis}

For each participant, risk perception scores were averaged across images, conditioning the data on risk situation and time of day. To measure PPFDM, responses to the preferences for formidable mates scale were summed across items for each participant. There was no significant difference in risk ratings, $t(156)=3.71, p=.711$, or PPFDM scores, $t(156)=-1.068, p=.287$ according to the order in which they were completed. Hence, we did not include questionnaire order in any of the analyses that will follow. PPFDM scores were mean centred prior to analysis. The risk perception data were analysed with a 2 time of day (day versus night) $\times 3$ risk situation (hotspots, safespots, versus male presence) ANCOVA, with PPFDM as the covariate. Alpha was set to .05 in the analysis. Significant results were further examined with Bonferonni corrected t-tests and Pearson's $r$.

\section{Results}

\section{Preliminary Analyses}

On average, women's risk perception scores fell around the mid-point of the scale ( $M=5.14$, $S D=1.88)$. There was a main effect for time of day; women rated their perceived risk of victimisation as higher for the night compared to the day images, $(M=4.60$, SEM $=.15$ versus $M=5.68$, SEM $=$ .13), $F(1,156)=257.05, p<.001, \eta_{p}{ }^{2}=.62$. Risk perception scores also varied significantly in relation to risk situation, $F(1,37)=254.38, p<.001, \eta_{p}{ }^{2}=.62$. Women perceived their risk as higher for the male images $(M=6.02$, SEM $=.14)$ compared to the crime hotspot images $(M=5.14, S E M=.14)$ and the safespot images $(M=4.26, S E M=.14)$; perceived risk was also significantly higher for the hotspot compared to the safespot images, all $p^{\prime} s<.001$. As such, the images affected feelings of risk in the manner that we had anticipated. The main effects, however, are qualified by significant interaction effects. Namely, a significant two-way interaction was obtained for risk situation and 
216

217

218

219

220

221

224

time of day, $F(1,312)=65.46, p<.001, \eta_{p}^{2}=.29$. Perceived risk was significantly higher at night compared to daytime for images of crime hotspots (mean difference $=1.15, p<.001$ ), safespots (mean difference $=.507, p<.001)$ and male presence (mean difference $=1.56, p<.001)$. There was a significant difference in perceived risk between each risk situation during both the day and night (all p's $<.001)$

PPFDM

As can be seen in Figure 2, women's risk perception scores were positively correlated with PPFDM in every risk situation, both during the day and during the night. Additionally, PPFDM was a significant predictor of risk perception scores, $F(1,156)=29.25, p<.001, \eta_{p}{ }^{2}=.16$. Women with relatively high PPFDM scores tended to perceive themselves as having a higher risk of victimisation ( $r$ $=.40, p<.001) .$. In addition, a significant three-way interaction was obtained for risk situation, time of day, and PPFDM, $F(1,312)=5.86, p<.01, \eta_{p}{ }^{2}=.04$. To investigate the three-way interaction effect, we analysed each situation separately, using repeated measures ANCOVAs, with time of day as the repeated measure and PPFDM as the covariate. Results indicated that the time of day $x$ PPFDM interaction effect was significant in only the male image condition, $F(1,156)=8.43, p=.004$, $\eta_{p}{ }^{2}=.05$. As can be seen in Figure 2, the effect emerged because the correlation between risk perception and PPFDM was smaller for the situation in which there was a shadowy figure of a male at night time compared to daytime ( $r=.39$ versus $r=.80$ versus, respectively), $z=5.749, p<.001$. All other interactions were nonsignificant.

\section{Discussion}

The findings of Study 1 suggest that the relationship between PPFDM and risk perceptions is general in nature. Contrary to Hypothesis 1, PPFDM was positively correlated with risk perceptions in crime hotspots and safespots. Additionally, PPFDM was positively correlated with risk perceptions in every situation, both at night and during the daytime. The strength of the association between 
PPFDM and risk was smaller when the image portrayed a lone man in the night compared to the other situations depicted. This suggests that regardless of individual differences in risk perception, women by and large tended to perceive the image of a male figure as risky. underlie the relationship between PPFDM and risk perceptions seem to be general rather than specific in nature. Women with stronger PPFDM tend to feel more at risk, regardless of the circumstances. Moreover, the order in which participants completed the risk perception measurements or the PPFDM scale did not influence scores, suggesting PPFDM may be a stable trait, rather than being influenced by the images depicting varied risk of victimisation. However, perhaps we did not find evidence that women with higher PPFDM are more in tune with environmental risks because the testing context did not afford a sensitive enough test. Specifically, had we tested women's risk perceptions in actual situations that varied with respect to victimisation risk cues, we may have found that the relationship between women's risk perceptions and PPFDM varied in relation to the level of risk present in the situation. they walked through a city centre, following a predetermined route that featured crime cues (e.g., alleyways, broken windows). They evaluated their risk in relation to several different types of crime (rape, robbery versus assault), perpetrated by a male versus female assailant. We also explored in Study 2 the multiple psychological dimensions of fear in relation to PPFDM, including fear of crime, perceived consequence seriousness, and perceived risk of victimization. However, as evidence suggests that perceived risk of victimization best defines fear of crime (e.g., Rountree \& Land, 1996; Gabriel \& Greve, 2003; Jackson, 2005; Warr, 1987), is strongly associated with fear of crime (e.g., Radar et al. 2007), differs by crime type (Reid \& Konrad, 2004), almost entirely mediates the association between crime cues (e.g., broken windows, graffiti, anti-social behaviour) and fear of crime (Ferraro et al. 1992), and contributes, along with perceived offense seriousness, to overall fear 
of victimisation (Warr \& Stafford, 1983), we used perceived risk as our primary dependent variable to assess the relationship between feelings of vulnerability and PPFDM. Indeed, women's fear of sexual assault seems to be based largely on their perceived risk (Fisher \& Sloan, 2003; Wilcox et al. 2006), which also contributes largely to behaviours to avoid victimisation (Ferraro, 1995). Finally, Snyder et al. 2011 posit that there are likely to be individual differences across women in the benefits afforded by a formidable mate. For example, women vary in both their attractiveness to assailants and their abilities to protect themselves from victimisation. Likewise, research shows variations in women's preferences for masculinity in males (e.g., Gangestad et al. 2004; Gildersleeve et al. 2013), in their risk perceptions (Šuklová \& Sarmány-Schuller, 2011) and in their avoidance of risky situations (e.g., Chavanne \& Gallup, 1998; Bröder \& Hohmann, 2003) over the menstrual cycle. To take account of potential cycle effects, we ensured that equal numbers of women participated in the high versus low fertility phase of the menstrual cycle. We also assessed women's general anxieties and body mass index (BMI) in Study 2. BMI has been shown to be related to fear of crime (Brown et al. 2014; Kodjebacheva et al. 2015) and feelings of vulnerability (Killias \& Clerici, 2000).

Study 2

Method

Participants

An eligible sample of forty naturally and regularly cycling women, ranging in age from 18 to $35(M=19.80$ years, $S D=3.37)$ participated in the study in return for course credit or payment. Informed consent was obtained from all women before participating, and the project received full ethical approval, as reviewed by the University of $x$ 's research ethics committee. Participants were recruited from a larger sample of women which responded to a prescreening questionnaire which checked eligibility for participation. Eligibility requirements included being between 18 and 35 years 
old, not using any form of hormonal contraceptives, and having a regular menstrual cycle (i.e., menses consistently occurring every 26-32 days).

Women were randomly assigned to participate on either days 1-3 (nonfertile phase, $n=21$ ) or days 12-16 (fertile phase, $n=19$ ) of their menstrual cycle. This was calculated using the forward cycle method (Grammer, 1993; Wideman et al. 2013) using information provided in the prescreening questionnaire. Participants were asked and reminded to inform the experimenter once their next menses had begun to further verify menstrual cycle phase during participation using the. Sixteen participants responded with their date of onset of next menses, 12 of which had participated in the fertile phase'. Ovulatory status was confirmed at the end of the study using the backwards count method (Haselton \& Gangestad, 2006) and a self-administered urine-based ovulation test.

\section{Materials and Procedure}

Participants reported to a laboratory at the start of the study. They were told that they were taking part in a project in collaboration with Leicestershire Police to understand feelings of personal safety in Leicester city centre. This cover story was employed to avoid disclosing to the participant the true aims of the research. After providing their consent, participants completed a pre-route questionnaire. This included questions about themselves (i.e., age, menstrual cycle, sexual orientation, relationship status and living arrangements), along with distractor questions, regarding their health and general lifestyle to disguise the research aims. Included in the questionnaire was the PPFDM scale measuring preference for formidable mates (see Snyder et al. 2011), as in Study 1. The order in which the PPFDM scale and the risk perception assessments were presented did not affect responses in Study 1. As such, the PPFDM scale was completed once, before participants went on the route around the city centre to assess how variations in vulnerability and risk perceptions would predict PPFDM. 

centre, including alleyways, backstreets, open areas and shopping areas (e.g., market stalls and retail stores). The route featured nine key points, including five crime hotspots (e.g., alleyways and back streets, see Figure 1), and four safespots (e.g., including open areas, and busy shopping areas, see figure $\mathrm{x}) .{ }^{1} \mathrm{~A}$ female research assistant escorted the research participant from the lab to the start of the route, and then walked with the participant along the route. We opted to only use female research assistants to reduce variability, as interviewer gender can impact fear of crime reports (e.g., Killias, \& Clerici, 2000). The research assistants were blind to participant responses on the previously aforementioned scales. Research assistants were instructed to avoid unnecessary conversation with the participant along the route so as to avoid distracting the participant from her surroundings, and to provoke feelings of being alone. The experimenter and participant stopped at each of the nine key points, in which the participant was asked to record their responses to the questions measuring their fear of crime on a sheet of paper. The experimenter was unaware of the responses recorded by the participants.

Gabriel \& Greve, 2003; Jackson, 2005; Killias \& Clerici, 2000; Rountree \& Land, 1996). Participants

\footnotetext{
${ }^{1}$ We initially defined crime hotspots as stereotypical indicators of situations where crime is more likely to occur, following suggestions from previous research (e.g., Broder \& Höhmann, 2003; Chavanne \& Gallup, 1998; Jones, Drury \& McBeath, 2011) such as alleyways, backstreets, deserted and dimly lit areas. However, whilst piloting the route we came across an additional location at the end of the route. This was a deserted pub with broken and boarded up windows, surrounded by litter. Despite not fitting our original definition of a crime hotspot, it came to our attention that it provoked feelings of vulnerability and risk of crime and thus we decided to include this as a key point at the very end of the route (hence including 5 crime hotspots and 4 safespots). We therefore used mean scores rather than the sum of risk scores for data analysis. Results do not differ with this crime hotspot included or omitted.
} 
were asked to respond as if they were alone in that particular location at the present time. The questionnaire began by asking participants to state in which type of location they were (e.g., residential street, alleyway, shop) to verify their perception of that location was veridical. The questionnaire proceeded to ask how safe they felt on a scale from 0 (very unsafe) to 10 (very safe). They were then asked about the extent of their fear of crime in that area, from 0 (no fear at all) to 10 (highly fearful). Afterwards, open-ended questions were asked regarding which particular crime they felt most afraid of becoming victim to in that location, and for what reason- that is, what outcome or consequence they feared as a result of becoming victim to that crime (e.g., injury). They were then asked to rate the perceived seriousness of that consequence on a scale from 0 (no negative consequences) to 10 (very serious consequences).

To measure perceived risk, participants were asked to report how likely on a scale of 0 (not likely at all) to 10 (extremely likely) they perceived their risk of becoming a victim of each crime. The crimes included: rape by a man, robbery by a man, robbery by a woman, physical assault by a man, and physical assault by a woman. Finally, they were asked about their feelings of vulnerability with regard to becoming a victim of crime on a scale from 0 (not vulnerable at all) to 10 (extremely vulnerable), and an open-ended question about which crime they felt particularly vulnerable to in that location.

On completion of the route, the participant and experimenter returned to the lab, wherein the participant took a self-administered urine based ovulation test and was given a full debrief detailing the true aims of the research.

Data analysis

We averaged women's risk perception scores, conditioning the data on location, crime type and perpetrator gender. To measure PPFDM, we summed the ratings women gave on the preferences for physically formidable and dominant mates scale. Finally, following guidelines for 
analysing the PANAS, we calculated scores for negative and positive affect separately (see Watson et al. 1988). Only 6 participants were in a relationship; thus, it was not possible to analyse current relationship status in relation to any of the other study variables.

\section{Preliminary Analyses}

Results

First we assessed whether women had interpreted the visual cues along the route in the manner that we had hoped. Towards this end, we conducted repeated measures t-tests on women's ratings of safety, fear of crime, vulnerability, and victimization consequences, with location as the repeated measures factor. Effect sizes were calculated using Cohen's $d$ (Cohen, 1988), with the Morris and DeShon's (2002) equation 8 correction for dependence among means for within-subjects designs. The results are presented in Table 1. As shown, women felt significantly less safe, reported higher levels of fear, felt more vulnerable, and perceived that the consequences of crime would be more serious for them in the crime hotspots compared to safespots. Additionally, we verified and found based on women's written responses that their perceptions were veridical with being in a hotspot versus safespot. Thus, women had perceived the visual cues of crime in the manner we had expected.

We also performed bivariate analyses of the fear of crime measures taken in hotspots and safespots in relation to PPFDM, negative affect and positive affect. The results are shown in Table 2 . PPFDM was positively and significantly associated with negative affect. As such, in the analyses that follow, we modelled the dependent variables with both PPFDM and negative affect included. PPFDM was significantly and positively correlated with the crime hotspot data, including perceptions of risk, vulnerability, and seriousness of consequences of victimisation. For the safespot data, PPFDM was significantly and positively correlated only with the perception of seriousness. 
PPFDM and fertility status were significantly and positively associated, $r_{s}(38)=.361, p=.033$,

indicating that fertile women preferred aggressive-formidability in mates. However, fertility status was not was not significantly related to women's risk perceptions in either crime hotspots, $r_{s}(38)=$ $.069, p=.67$, or safespots, $\left.r_{s}(38)=-.011, p=.95\right)$, nor did it significantly interact with any of the other predictor variables in predicting risk perceptions. Thus, fertility status will not be discussed any further.

PPFDM and Perceived Risk of Robbery and Physical Assault by Male and Female Perpetrators

We began our analysis by examining women's reports regarding their perceived risk of crime as they walked through crime hotspots and safespots in the city centre. To test our hypotheses, we conducted a 2 (location) $\times 2$ (assailant gender) $\times 2$ (crime type) repeated measures ANCOVA on the personal risk perception scores, with the mean centred PPFDM and negative affect scores entered as covariates. who reported relatively high rates of perceived risk tended to score higher on the PPFDM scale, $r=$ $.35, p<.05$. Negative affect was not associated with risk perceptions, $F(1,37)=.26, \eta_{p}{ }^{2}=.00$. Women perceived their risk of crime as being significantly higher in crime hotspots compared to safespots ( $M$ $=5.77, S E M=.25$ versus $M=3.66, S E M=.21$, respectively $)$, a significant main effect for location, $F(1$, $37)=64.66, p<.001, \eta_{p}^{2}=.64$. Women also perceived themselves as having a significantly higher risk of being attacked by a male compared to female assailant $(M=5.29, S E M=.21$ versus $M=4.14$, SEM $=.23$, respectively), a significant main effect for assailant gender, $F(1,37)=35.15, p<.001, \eta_{p}^{2}=.49$. Finally, a significant main effect for crime type was also obtained, with women rating their risk of respectively), $F(1,37)=38.41, \mathrm{p}<.001, \mathrm{\eta}_{\mathrm{p}}^{2}=.51$. 
Figure 3 displays the relationship between PPFDM and fear of crime by assailant gender and

404

405

406

407

408

409

410

411

412

413

414

415

416

417

418

419

420

421

422

423

424

location. The interaction between PPFDM and location was not significant; thus, Hypothesis 1, which stated the relationship between PPFDM and risk is stronger in hotspots compared to safespots, was not supported. Additionally, the interaction between PPFDM and assailant gender did not reach statistical significance, $F(1,37)=2.08, p=.16, \eta_{p}^{2}=.05$. Therefore, Hypothesis 2 , which predicted a stronger relationship between PPFDM and risk for male- compared to female-perpetrated crimes, was not supported.

There were several 2-way interaction effects: assailant gender and location, $F(1,37)=12.39$, $p<.001, \eta_{p}^{2}=.25$, assailant gender and crime type, $F(1,37)=5.76, p<.05, \eta_{p}^{2}=.14$, and location and crime type, $F(1,37)=11.69, p<.01, \eta_{p}^{2}=.24$. These relationships are depicted in Figure 4. Pairwise comparisons adjusted for multiple comparisons using the Bonferroni correction were used to examine these interactions. The assailant gender by location interaction showed that whilst there was a significant difference in perceived risk of male- versus female-perpetrated crimes in both hotspots and safespots, the gender difference was larger in hotspots (mean difference $=1.44, S E=$ .24. $p<.001$ ) compared to safespots (mean difference $=.85, S E=.17, p<.001$ ). Similarly, whilst perceived risk was significantly higher in hotspots compared to safespots regardless of perpetrator gender, the location difference was larger for male (mean difference $=2.4, p<.001$ ) compared to female-perpetrated crimes (mean difference $=1.81, p<.001$ ). Secondly, although the perceived risk of a male compared to a female perpetrator was higher for both robbery (mean difference $=1.00, S E$ $=.20, p<.001$ ) and physical assault (mean difference $=1.28, S E=.201, p<.001$ ), the gender difference was slightly greater for physical assault. The risk of robbery was perceived as higher than the risk of assault regardless of gender, but the crime type difference was slightly higher for femaleperpetrated $($ mean difference $=.991, p<.001)$ compared to male-perpetrated crimes mean difference $=.71, p<.001)$. Finally, whilst the perceived risk of robbery was significantly higher than perceived risk of physical assault in hotspots (mean difference $=.43, S E=.13, p<.01$ ) and safespots (mean difference $=1.28, S E=.231, p<.001$ ), robbery was perceived as being particularly more likely 
compared to physical assault in the safespots. The difference in perceived risk according to location was greater for physical assault crimes (mean difference $=2.54, p<.001$ ) compared to robbery (mean difference $=1.68, p<.001)$.

\section{Perceived Personal Risk of Rape versus Robbery and Physical Assault by Male Perpetrators}

To test Hypothesis 3, which posited that the relationship between PPFDM and risk perceptions is stronger for sexual assault compared to other crimes, we conducted a 2 (location) $\times 3$ (crime type-for only male-perpetrated crime) mixed model ANCOVA on the personal risk of crime scores, entering the mean centred PPFDM and negative affect scores as the covariates. Figure 3 displays the results.

In keeping with the previous results, PPFDM was a significant predictor of perceived risk, $F(1$, $37)=7.37, p<.05, \eta_{p}{ }^{2}=.17$. Women who expressed a stronger preference for formidable mates also tended to perceive themselves as having a higher risk of crime, $r=.40, p<.05$. Risk was not associated with negative affect, $F(1,37)=.38, p=.54, \eta_{p}{ }^{2}=.01$. However, women perceived themselves as having a greater risk of crime in hotspots compared to safespots $(M=6.48, S E M=.27$ versus $M=3.56, S E M=.21$, respectively), $F(1,37)=101.79, p<.001, \eta_{p}{ }^{2}=.73$, and women's risk perceptions significantly varied in relation to crime type (rape $M=4.49, S E M=.21$; robbery $M=$ $5.65, \operatorname{SEM}=.21 ;$ assault $M=4.94, \operatorname{SEM}=.22), F(1,37)=26.99, p<.001, \eta_{\mathrm{p}}{ }^{2}=.42$. PPFDM did not interact with location however, $F(2,74)=.82, p=.44, \eta_{p}^{2}=.02$. As shown in Figure 3 , the strength of the association between PPFDM and risk perceptions was similar across crime type. Thus, support for Hypothesis 3, which proposed that PPFDM would be especially predictive of risk perceptions for rape compared to other types of crimes, was not found.

There was a significant location $x$ crime type interaction, $F(2,74)=25.02, p<.001, \eta_{p}^{2}=.40$. Pairwise comparisons adjusted for multiple comparisons using the Bonferroni correction showed that perceived risk was significantly higher for hotspots compared to safespots for all crimes (all $p^{\prime} s$ 
$<.001)$. However, whilst there was no difference in perceived risk for male-perpetrated robbery, assault or rape in the hotspots (all p's > .122), perceived risk for these male-perpetrated crimes differed significantly in the safespots. Perceived risk for male-perpetrated robbery was significantly higher than perceived risk for male-perpetrated rape (mean difference $=2.16, S E$ mean difference $=$ $.32, p<.001$ ) and for physical assault (mean difference $=1.16$, SE mean difference $=.25, p<.001$ ). Perceived risk of male-perpetrated physical assault was significantly higher than perceived risk of rape (mean difference $=.995$, SE mean difference $=.194, p<.001$ ). No other statistically significant relationships were found $\left(F^{\prime} \mathrm{s}<1.40\right)$.

\section{Discussion}

Previous research has found that fear of crime is related to preferences for physically formidable and dominant mates (Snyder et al. 2011). Life history models suggest that cues of environmental risk during childhood, including attachment styles and psychosocial stress, predict reproductive strategies in later adulthood (e.g., see Del Giudice, 2009). Further, Snyder and colleagues found evidence that PPFDM is a relatively stable trait, with PPFDM predicted by prevalence of crime during childhood and subjective fear of crime rather than current actual crime levels. They proposed that feelings of worry in relation to becoming a crime victim are related to PPFDM due to the protection that a physically formidable mate can offer. However, it has been suggested that reproductive strategies may adjust with changing environments (see Del Giudice, 2009). Therefore, as PPFDM seems to be related to vulnerability, we tested whether the strength of the association between PPFDM and fear of crime is stronger for situations in which the risk and costs of victimisation, and hence, the need for protection, are higher. If women with a high PPFDM are particularly sensitive to cues indicative of victimisation risk, then PPFDM and risk perceptions should correspond most strongly when the risk of crime is high. On the other hand, if PPFDM is predictive of risk, even in safe environments, this would suggest that women with strong PPFDM generally feel more vulnerable compared to their counterparts. To investigate, we had women 
evaluate their risk of crime in situations depicted in images that varied in the presence of crime risk cues (Study 1). We also had women rate their risk of victimisation as they walked through crime hotspots and safespots in a city centre (Study 2).

In Study 1, we found that women evaluated their risk of victimisation as higher in situations where there was a lone shadowy male figure and when there were other cues indicative of crime (e.g., alleyways, night time). In Study 2, we found that women felt more vulnerable, felt less safe, perceived their risk of crime to be higher, and they were more concerned about the victimisation seriousness (hereby, these results will be collectively referred to as 'fear of crime') in the crime hotspots compared to safespots. Therefore, women as a whole were sensitive to the cues in their environment, which in turn affected their perceptions of risk and fear of crime.

We tested whether strong preferences for dominant and formidable mates was associated with greater perceived victimisation risk, particularly in situations in which the risk of victimisation is highest, including situations in which there are crime cues, the assailant is male, and the crime is sexual assault. The findings suggest that the psychological mechanism underlying the association between perceived risk of victimisation and PPFDM is general in nature. Women who tended to fear crime the most and who viewed themselves as having a relatively high victimization risk, tended to prefer physically formidable and dominant mates more strongly than other women. Thus, our results are in keeping with Snyder and colleagues' (2011) proposal that PPFDM may not be related to actual prevailing rates of violence, but rather appears to be associated with women's self-assessed vulnerability.

Previous research suggests that women avoid risky situations during phases of peak fertility (e.g., Bröder \& Hohmann, 2003; Chavanne \& Gallup, 1998), when sexual victimisation is arguably more costly due to the increased chance of conception. Fessler and colleagues (2014) suggest that a woman's assets e.g., reproductive fitness and survival, are more at risk of incurring costs of victimisation at peak fertility. Whilst we did not find fertility status to be associated with perceptions 
503

504

505

506

507

508

509

510

511

512

513

514

515

516

517

518

519

520

521

522

523

524

525

526

527

528

of risk or fear of victimisation, fertility status was associated with PPFDM. Snyder et al. (2011)

suggest that women with higher vulnerability to crime victimisation should have higher preferences for formidable mates. Fertile compared to nonfertile women indeed reported a higher PPFDM. This finding may suggest that the higher asset risks associated with ovulation, and thus increased vulnerability to crime is associated with a higher need for protection from a formidable mate. However, some traits associated with a formidable mate such as tall and broad shoulders are associated with masculinity, which signals quality genetics (Tybur \& Gangestad, 2011; Scott, Clark, Boothroyd \& Penton-Voak, 2013). Preference for such traits do vary over the menstrual cycle (e.g, Gangestad et al. 2004; Gildersleeve et al. 2013). Further examination of the influence of fertility status on PPFDM would be an interesting avenue for further research.

Negative affect was significantly associated with PPFDM. The emotions scared, nervous, jittery and afraid contribute to the measure of negative affect in the PANAS, and fear has been shown to be one of two main components of the negative affect scale (Ebesutani et al. 2011). Therefore, our results are in step with previous findings, showing that negative affect and fear are correlated. This finding may suggest that preference for physically formidable and dominant mates is tied to a general individual differences factor, with women who feel the most afraid and vulnerable having strong preferences for physically formidable and dominant mates. The data suggest that women who generally feel more vulnerable, regardless of the situation, have a high PPFDM, and women who generally feel less vulnerable have a lower PPFDM. This may suggest overall individual differences in risk assessments, which in turn influence mate preferences.

Women are likely to vary in their own abilities to defend against a potential antagonist and the importance they place on a formidable mate. One way we assessed this possibility to estimate women's ability to defend themselves was through BMI measurements, and we found that BMI was not associated with either fear of crime or PPFDM. However, there may be other individual difference factors that underlie the relationship between PPFDM and fear of crime, and this warrants further examination. Women feel more or less vulnerable to victimisation for a number of 
reasons. First, childhood experiences with physical threats may play a large role, and may explain the stability of PPFDM into adulthood (e.g., Sherman et al. 2015). For example, an interesting avenue for future research would be to examine the development of PPFDM as a function of childhood experiences of crime, heightened vulnerability, and limited protection. Other factors that might affect women's PPFDM could include the psychological ability to cope with threat, the perceived value of a women's assets (e.g., the ability to defend herself and the evolutionary costs to fitness that she is likely to suffer from violent victimisation, see Fessler et al. 2015) or past victimisation experiences with strangers versus mates (Cate et al. 2003). relatively stable trait, which is unlikely to vary over short time spans. However, they argued that before definitive conclusions could be made regarding the stability of fear of crime, it was necessary to assess fear of crime with more ecologically valid primes. Indeed, using real life crime hotspots

541 versus safespots, we found fear to be more variable; fear varied in response to the environment. As women walked around the city centre, fear of crime ratings differed between crime hotspots and safespots, suggesting that fear of crime may not be a stable trait. Perceived risk appeared to reflect actual crime rates; perceived risk of robbery was higher than perceived risk of physical assault and sexual assault, which is in line with crime statistics for Leicestershire. ${ }^{2}$ However, despite finding PPFDM to be higher in women that report higher perceived risk of victimisation, the association between PPFDM and perceived risk of victimisation did not vary according to location and crime type. As such, our findings regarding the stability of PPFDM are in keeping with Snyder et al.'s

549 (2011), suggesting that PPFDM is a stable trait. However, our findings are not in line with Marzoli et al's (2013) who found primes regarding the prevalence of violence to influence mate preferences. However, firstly, there may be evolutionary advantages of the stability of such psychological

\footnotetext{
${ }^{2}$ Crime statistics for Leicester were accessed from the Office for National Statistics website (http://www.ons.gov.uk/ons/publications/re-reference-tables.html?edition=tcm\%3A77-328153). Data relates to police recorded crime by offence group and police force area in 2013/14, which shows that theft (total recorded crime: 33,497$)$ was more prevalent than violence against a person $(10,822)$, and sexual offences $(1,137)$
} 
552

mechanisms. Our finding of stability in the relationship between PPFDM and risk may be due to the fact that it may not be adaptive for women to engage in a risk assessment each time they encounter a new environment or a potential mate. Moreover, we asked women about their preferences for formidability and dominance in a long-term mate specifically. Snyder et al. (2008) found that relationship type (short- versus long-term) moderated changes in women's trade-off for dominance versus prestige in a partner. The trade-off faced in the commitment versus protection afforded by a physically formidable and dominant mate should not fluctuate in a long-term partner like it would for a short-term partner. Rather, it makes sense that women who generally feel less able to protect themselves, and thus vulnerable to criminal victimisation, would reap the protective benefits from a physically formidable and dominant long-term mate regardless of the situation. Similarly, it may not be considered adaptive for preferences for a long-term mate to continuously update as this is likely to compromise relationship commitment, unlike for a short-term mate. Had we asked about preferences for a short-term mate, or simply not clarified relationship type, the relationship between PPFDM and perceived risk may have been less stable. However, as discussed by Del Giudice (2009), stability in the relationship between risk perceptions and PPFDM may only be considered adaptive in relatively stable environments.

Secondly, we have not considered the flexibility of the mechanism over longer-term time scales or in response to the environment, as the trade-off of having a formidable mate fluctuates. It is possible that the mechanism may recalibrate according to prevalence of threat in the environment. Future research could consider assessing the relationship between PPFDM and vulnerability to victimisation over longer time periods, such as women who have moved between the city and the countryside. Future research could also consider assessing PPFDM in a real-life setting, that is, in crime hotspots versus safespots as fear and risk of crime varies to determine whether PPFDM varies with cues of crime. Indeed, Marzoli et al. (2013) found primes regarding the prevalence of violence to influence mate preferences. 

hence, we could not determine the role that childhood experiences played in the development of PPFDM. Additionally, our study cannot rule out the possibility that the association between PPFDM and perceived risk of crime is accounted for by a social learning explanation. For example, children that grew up in areas with higher prevalence of crime may experience their mother's choice of partner as being physically formidable and dominant as protection from criminal victimisation, and subsequently learnt from this behaviour. The sample size in Study 2 could also be considered a limitation. We prioritised data collection in the real world to investigate the priming effects that authentic crime hotspots had on fear of crime at the cost of a relatively small sample size. Nonetheless, it is important to note that our manipulation of fear of crime was effective, and that our main research finding of an association between vulnerability and PPFDM is similar to previous research (e.g., Snyder et al. 2011) thus providing convergent data. Therefore, future research should aim to replicate this methodology using both a larger sample size and a between-subjects manipulation of location, while assessing whether PPFDM varies according to location and update in response to cues of risk (i.e., in crime hotspots versus safespots).

In summary, across two studies, our findings indicate that the relationship between perceived vulnerability and preferences for the protection offered by a physically formidable and dominant male is robust. We extended previous research by examining the specificity of the cognitive mechanisms underlying the association between PPFDM and fear of crime under ecologically valid conditions. We tested the specificity of PPFDM, examining whether women with strong PPFDM perceived greater vulnerability to relatively more evolutionarily costly crimes. However, our results indicated that PPFDM may be a stable trait. We conclude that women with strong PPFDM feel relatively more at risk, fearful, and vulnerable to criminal victimisation compared to their counterparts, regardless of whether there are situational risk factors present. 
604 University of Leicester School of Psychology's Research Committee. We would also like to thank

605 Samantha Palmer, Beth Shelton, Ellen Green, Shaquille Stephen, Olga Pacholec and Emma Shillcock

606 for their help with data collection. We also thank the Editor, Jeffrey Snyder and the three

607 anonymous reviewers their insightful comments and suggestions on this manuscript.

h.flowe@lboro.ac.uk. 
Abdullah, A., Marzbali, M. H., Bahauddin, A., \& Tilaki, M. J. M. (2015). Broken Windows and Collective Efficacy. SAGE Open, 5(1), 1-11, DOI: 10.1177/2158244014564361

614

615

616

617

618

Archer, J., \& Thanzami, V. (2009). The relation between mate value, entitlement, physical aggression, size and strength among a sample of young Indian men. Evolution and Human Behavior, 30(5), 315-321. http://dx.doi.org/10.1016/j.evolhumbehav.2009.03.003

Atkeson, B., Calhoun, K., Resick, P. and Ellis, E. (1982). Victims of rape: Repeated assessment of depressive symptoms. Journal of Consulting and Clinical Psychology, 50, 96-102. http://dx.doi.org/10.1037/0022-006X.50.1.96

Buss, D. M. (1994). The evolution of desire: Strategies of human mating. New York: Basic Books.

Buss, D. M., \& Schmitt, D. P. (1993). Sexual strategies theory: an evolutionary perspective on human mating. Psychological review, 100(2), 204. http://dx.doi.org/10.1037/0033-295X.100.2.204

Bleske-Rechek, A. L., \& Buss, D. M. (2001). Opposite-sex friendship: Sex differences and similarities in initiation, selection, and dissolution. Personality and Social Psychology Bulletin, 27(10), 13101323. http://dx.doi.org/10.1177/01461672012710007

Bröder, A., \& Hohmann, N. (2003). Variations in risk taking behavior over the menstrual cycle: An improved replication. Evolution and Human Behavior, 24(6), 391-398. http://dx.doi.org/10.1016/S1090-5138(03)00055-2

Brown, B. B., Werner, C. M., Smith, K. R., Tribby, C. P., \& Miller, H. J. (2014). Physical activity mediates the relationship between perceived crime safety and obesity. Preventive medicine, 66, 140-144. http://dx.doi.org/10.1016/j.ypmed.2014.06.021

Cate, K. L., Bassett, J. F., \& Dabbs Jr, J. M. (2003). Fear primes may not affect women's implicit and explicit mate preferences. Journal for Articles in Support of the Null Hypothesis, 1(4), 49-56.

Chavanne, T. J., \& Gallup, G. G. (1998). Variation in risk taking behavior among female college students as a function of the menstrual cycle. Evolution and Human Behavior, 19(1), 27-32. http://dx.doi.org/10.1016/S1090-5138(98)00016-6 
638 Cohen, J. (1988). Statistical power analysis for the behavioral sciences (2nd ed.). Hillsdale, NJ: Lawrence Earlbaum Associates.

De Leon, J. P., \& Cohen, J. H. (2005). Object and walking probes in ethnographic interviewing. Field Methods, 17(2), 200-204. http://dx.doi.org/10.1177/1525822X05274733

Del Giudice, M. (2009). Sex, attachment, and the development of reproductive strategies. Behavioral and Brain Sciences, 32(1), 1-21.

Dobzhansky, T. (1956). What is an adaptive trait? American Naturalist, 90(855), 337-347.

Duntley, J. D., \& Shackelford, T. K. (2012). Adaptations to avoid victimization. Aggression and Violent Behavior, 17(1), 59-71. doi:10.1016/j.avb.2011.09.008

Ebesutani, C., Smith, A., Bernstein, A., Chorpita, B. F., Higa-McMillan, C., \& Nakamura, B. (2011). A bifactor model of negative affectivity: Fear and distress components among younger and older youth. Psychological assessment, 23(3), 679-691. http://dx.doi.org/10.1037/a0023234

Ferraro, K. F. (1995). Fear of crime: Interpreting victimization risk. Albany, NY: State University of New York Press.

Ferraro, K. F. (1996). Women's fear of victimization: Shadow of sexual assault? Social Forces, 75(2), 667-690. http://dx.doi.org/10.2307/2580418

Ferraro, K. F., \& LaGrange, R. L. (1987). The measurement of fear of crime. Sociological inquiry, 57(1), 70-97. http://dx.doi.org/10.1111/j.1475-682X.1987.tb01181.x

Fessler, D. M., Holbrook, C., \& Fleischman, D. S. (2015). Assets at risk: Menstrual cycle variation in the envisioned formidability of a potential sexual assailant reveals a component of threat assessment. Adaptive Human Behavior and Physiology, 1, 270-290 http://dx.doi.org/10.1007/s40750-014-0006-0 
660

661

662

663

664

665

666

667

668

669

670

671

672

673

674

675

676

677

678

679

680

681

682

683

Fisher, B. S., \& Sloan III, J. J. (2003). Unraveling the fear of victimization among college women: Is the "shadow of sexual assault hypothesis" supported? Justice Quarterly, 20(3), 633-659. http://dx.doi.org/10.1080/07418820300095641

Fleming, A. S., Corter, C., Stallings, J., \& Steiner, M. (2002). Testosterone and prolactin are associated with emotional responses to infant cries in new fathers. Hormones and Behavior, 42, 399-413. http://dx.doi.org/10.1006/hbeh.2002.1840

Gabriel, U., \& Greve, W. (2003). The psychology of fear of crime. Conceptual and methodological perspectives. British Journal of Criminology, 43(3), 600-614. http://dx.doi.org/10.1093/bjc/43.3.600

Gangestad, S. W., Simpson, J. A., Cousins, A. J., Garver-Apgar, C. E., \& Christensen, P. N. (2004). Women's preferences for male behavioral displays change across the menstrual cycle. Psychological Science, 15, 203-207. doi:10.1111/j.0956-7976.2004.01503010.x.

Gildersleeve, K., DeBruine, L., Haselton, M. G., Frederick, D. A., Penton-Voak, I. S., Jones, B. C., \& Perrett, D. I. (2013). Shifts in women's mate preferences across the ovulatory cycle: A critique of Harris (2011) and Harris (2012). Sex roles, 69(9-10), 516-524.

\section{http://dx.doi.org/10.1007/s11199-013-0273-4}

Gottschall, J.A., \&Gottschall, T.A. (2003). Are per-incident rape-pregnancy rates higher than perincident consensual pregnancy rates? Human Nature, 14, 1-20. http://dx.doi.org/10.1007/s12110-003-1014-0.

Grammer, K. (1993). 5-a-Androst-16en-3a-on: a male pheromone? A brief report. Ethology and Sociobiology, 14, 201-208. http://dx.doi.org/10.1016/0162-3095(93)90006-4

Greiling, H., \& Buss, D. M. (2000). Women's sexual strategies: The hidden dimension of extra-pair mating. Personality and individual Differences, 28(5), 929-963. 
684

685

686

687

688

689

690

691

692

693

694

695

696

697

698

699

700

701

702

703

704

705

706

707

708

Haselton, M. G., \& Gangestad, S.W. (2006). Conditional expression of women's desires and men's mate guarding across the ovulatory cycle. Hormones and Behavior, 49, 509-518. doi:10.1016/j.yhbeh.2005.10.006

Hawley, P. H. (2003). Prosocial and coercive configurations of resource control in early adolescence: A case for the well-adapted Machiavellian. Merrill-Palmer Quarterly, 49, 279-309. http://dx.doi.org/10.1353/mpq.2003.0013

Jackson, J. (2005). Validating new measures of the fear of crime. International Journal of Social Research Methodology, 8(4), 297-315. http://dx.doi.org/10.1080/13645570500299165

Jones, P., Drury, R., \& McBeath, J. (2011). Using GPS-enabled mobile computing to augment qualitative interviewing: Two case studies. Field methods, 23(2), 173-187. http://dx.doi.org/10.1177/1525822X10388467

Killias, M., \& Clerici, C. (2000). Different measures of vulnerability in their relation to different dimensions of fear of crime. British Journal of Criminology, 40(3), 437-450. http://dx.doi.org/10.1093/bjc/40.3.437

Kodjebacheva, G., Koleilat, M., \& Kruger, D. J. (2015). Depressive Symptoms Mediate the Association Between Fear of Crime and Higher Body Mass Index. American Journal of Health Promotion. In Press. doi: 10.4278/ajhp.140103-ARB-6

Lorber, M. F., \& O'leary, K. D. (2004). Predictors of the persistence of male aggression in early marriage. Journal of family violence, 19(6), 329-338. http://dx.doi.org/10.1007/s10896-0040678-5

Marzoli, D., Moretto, F., Monti, A., Tocci, O., Roberts, S. C., \& Tommasi, L. (2013). Environmental influences on mate preferences as assessed by a scenario manipulation experiment. PloS one, 8(9), e74282.

McKibbin, W. F., Shackelford, T. K., Goetz, A. T., Bates, V. M., Starratt, V. G., \& Miner, E. J. (2009). Development and initial psychometric assessment of the rape avoidance inventory. 
Personality and Individual Differences, 46(3), 336-340.

http://dx.doi.org/10.1016/j.paid.2008.10.026

Morris, S. B., \& DeShon, R. P. (2002). Combining effect size estimates in meta-analysis with repeated measures and independent-groups designs. Psychological Methods, 7, 105-125.

Office for National Statistics (2013). Crime Statistics, Nature of Crime tables, 2011/12. Timing of when incidents of violence occurred, 2003/04 to 2011/12 Crime Survey for England and Wales. Retrieved from: http://www.ons.gov.uk/ons/publications/re-referencetables.html?edition=tcm\%3A77-296029

Perilloux, C., Duntley, J. D., \& Buss, D. M. (2012). The costs of rape. Archives of sexual behavior, 41(5), 1099-1106. doi: 10.1007/s10508-011-9863-9.

Reid, L. W., \& Konrad, M. (2004). The gender gap in fear: Assessing the interactive effects of gender and perceived risk on fear of crime. Sociological Spectrum, 24(4), 399-425. http://dx.doi.org/10.1080/02732170490431331

Rountree, P. W., \& Land, K. C. (1996). Perceived risk versus fear of crime: Empirical evidence of conceptually distinct reactions in survey data. Social forces, 74(4), 1353-1376. http://dx.doi.org/10.2307/2580354

Sell, A., Tooby, J., \& Cosmides, L. (2009). Formidability and the logic of human anger. Proceedings of the National Academy of Sciences, 106(35), 15073-15078. http://dx.doi.org/10.1073/pnas.0904312106

Sherman, A.K., Minich, S.H., Langen, T.A., Skufca, J., \& Wilke, A. (2015). Are college students' assessments of threat shaped by the dangers of their childhood environment? Journal of Interpersonal Violence, 1-20. http://dx.doi.org/10.1177/0886260515572473

Smuts, B. (1992). Male aggression against women: An evolutionary perspective. Human Nature, 3, 144. http://dx.doi.org/10.1007/BF02692265 
Snyder, J. K., Fessler, D. M., Tiokhin, L., Frederick, D. A., Lee, S. W., \& Navarrete, C. D. (2011). Tradeoffs in a dangerous world: Women's fear of crime predicts preferences for aggressive and formidable mates. Evolution and Human Behavior, 32(2), 127-137. http://dx.doi.org/10.1016/j.evolhumbehav.2010.08.007

Snyder, J., \& Fessler, D. (2013). Fear does not correspond to higher costs of rape among married women. Journal of Evolutionary Psychology, 11(2), 49-64. doi: 10.1556/JEP.11.2013.2.1

Šukolová, D., \& Sarmany-Schuller, I. (2011). Fluctuating perception of selected risk situations with respect to hormonal changes during menstrual cycle. Studia Psychologica, 53(1), 3.

Thornhill, R., \& Palmer, C. (2000). A natural history of rape. Cambridge, MA: MIT Press

Ware Jr, J. E., Kosinski, M., \& Keller, S. D. (1996). A 12-Item Short-Form Health Survey: construction of scales and preliminary tests of reliability and validity. Medical care, 34(3), 220-233. http://dx.doi.org/10.1097/00005650-199603000-00003

Warr, M. (1985). Fear of rape among urban women. Social Problems, 32, 238-250. http://dx.doi.org/10.2307/800684

Warr, M. (1987). Fear of victimization and sensitivity to risk. Journal of quantitative criminology, 3(1), 29-46. http://dx.doi.org/10.1007/BF01065199

Warr, M., \& Stafford, M. (1982). Fear of victimization: A look at the proximate causes. Social Forces 61(4), 1033-1043. http://dx.doi.org/10.2307/2578277

Watson, D., Clark, L. A., \& Tellegen, A. (1988). Development and validation of brief measures of positive and negative affect: the PANAS scales. Journal of personality and social psychology, 54(6), 1063. http://dx.doi.org/10.1037/0022-3514.54.6.1063

Wideman, L., Montgomery,M. M., Levine, B. J., Beynnon, B. D., \& Shultz, S. J. (2013). Accuracy of calendar-based methods for assigning menstrual cycle phase in women. Sports Health: $A$ Multidisciplinary Approach, 5, 143-149. http://dx.doi.org/10.1177/1941738112469930 
757

758

759

760

761

762

763

764

765

766

767

768
Wilcox, P., May, D. C., \& Roberts, S. D. (2006). Student weapon possession and the "fear and victimization hypothesis": Unravelling the temporal order. Justice Quarterly, 23(4), 502-529. http://dx.doi.org/10.1080/07418820600985362

Wilson, M., \& Mesnick, S. L. (1997). An empirical test of the bodyguard hypothesis. In Feminism and evolutionary biology (pp. 505-511). Springer US. http://dx.doi.org/10.1007/978-1-4615$\underline{5985-6 \quad 21}$

Zhoa, J. S., Lawton, B., \& Longmire, D. (2015). An examination of the micro-level crime - fear of crime link. Crime and Delinquency, 61, 19-44. http://dx.doi.org/10.1177/0011128710386203 

Ratings in Crime Hotspots versus Safespots.

\begin{tabular}{lccccc}
\hline & Hotspots & Safespots & $\mathrm{t}(39)$ & $\mathrm{P}$ & Cohen's $d$ \\
\cline { 2 - 6 } Safety & $4.16(1.83)$ & $7.53(1.57)$ & -9.88 & $<.0001$ & -1.56 \\
Fear of Crime & $5.88(2.04)$ & $3.96(1.77)$ & 6.06 & $<.0001$ & .97 \\
Consequences & $7.26(1.74)$ & $4.97(1.93)$ & 8.57 & $<.0001$ & 1.38 \\
Vulnerability & $6.08(1.82)$ & $3.71(1.55)$ & 8.46 & $<.0001$ & 1.36 \\
\hline
\end{tabular}

771 
774 Table 2. Zero-order Correlation Coefficients Across the Covariates.

\begin{tabular}{|c|c|c|c|c|c|c|c|c|c|c|c|c|c|c|}
\hline & 2 & 3 & 4 & 5 & 6 & 7 & 8 & 9 & 10 & 11 & 12 & 13 & 14 & 15 \\
\hline 1 PPFDM & .129 & $.361^{*}$ & .212 & $.359^{*}$ & -.019 & .195 & $.396^{*}$ & $.342^{*}$ & $.349^{*}$ & -.144 & -.112 & $.351^{*}$ & .168 & .231 \\
\hline 2 Positive Affect & & -.168 & .137 & -.182 & -.015 & -.092 & .009 & -.105 & -.006 & $.317^{*}$ & .006 & .127 & .017 & $.340^{*}$ \\
\hline 3 Negative Affect & & & -.180 & .142 & -.123 & .026 & -.091 & .110 & .163 & .020 & -.107 & -.202 & -.088 & -.090 \\
\hline $4 \mathrm{BMI}$ & & & & -.132 & .132 & -.098 & .106 & -.176 & .036 & -.046 & .011 & .234 & -.051 & .214 \\
\hline 5 British Crime Survey & & & & & -.234 & .179 & .053 & $.369^{*}$ & .232 & $-.409^{* *}$ & -.098 & .053 & .265 & .207 \\
\hline 6 City Hotspot Safety Perception & & & & & & $-.368^{*}$ & -.209 & $-.496^{* *}$ & $-.471^{* *}$ & .195 & -.036 & .002 & -.119 & -.239 \\
\hline 7 City Hotspot Fear of Crime & & & & & & & $.558^{* *}$ & $.579^{* *}$ & $.597^{* *}$ & .080 & $.460^{* *}$ & $.334^{*}$ & .175 & .257 \\
\hline $\begin{array}{l}8 \text { City Hotspot Consequence } \\
\text { Seriousness }\end{array}$ & & & & & & & & $.650^{* *}$ & $.709^{* *}$ & .073 & .238 & $.591^{* *}$ & $.411^{\text {** }}$ & .247 \\
\hline 9 City Hotspot Vulnerability & & & & & & & & & $.732^{* *}$ & -.183 & .217 & .215 & $.461^{* *}$ & .198 \\
\hline 10 City Hotspot Risk Perception & & & & & & & & & & -.091 & .272 & $.317^{*}$ & .192 & $.378^{*}$ \\
\hline 11 City Safes pot Safety Perception & & & & & & & & & & & .069 & -.116 & -.132 & -.201 \\
\hline 12 City Safespot Fear of Crime & & & & & & & & & & & & .203 & $.344^{*}$ & .306 \\
\hline $\begin{array}{l}13 \text { City Safespot Consequence } \\
\text { Seriousness }\end{array}$ & & & & & & & & & & & & & $.461^{* *}$ & $.548^{* *}$ \\
\hline 14 City Safesoit Vulnerability & & & & & & & & & & & & & & $.617^{* *}$ \\
\hline 15 City Safespot Risk Perception & & & & & & & & & & & & & & \\
\hline
\end{tabular}



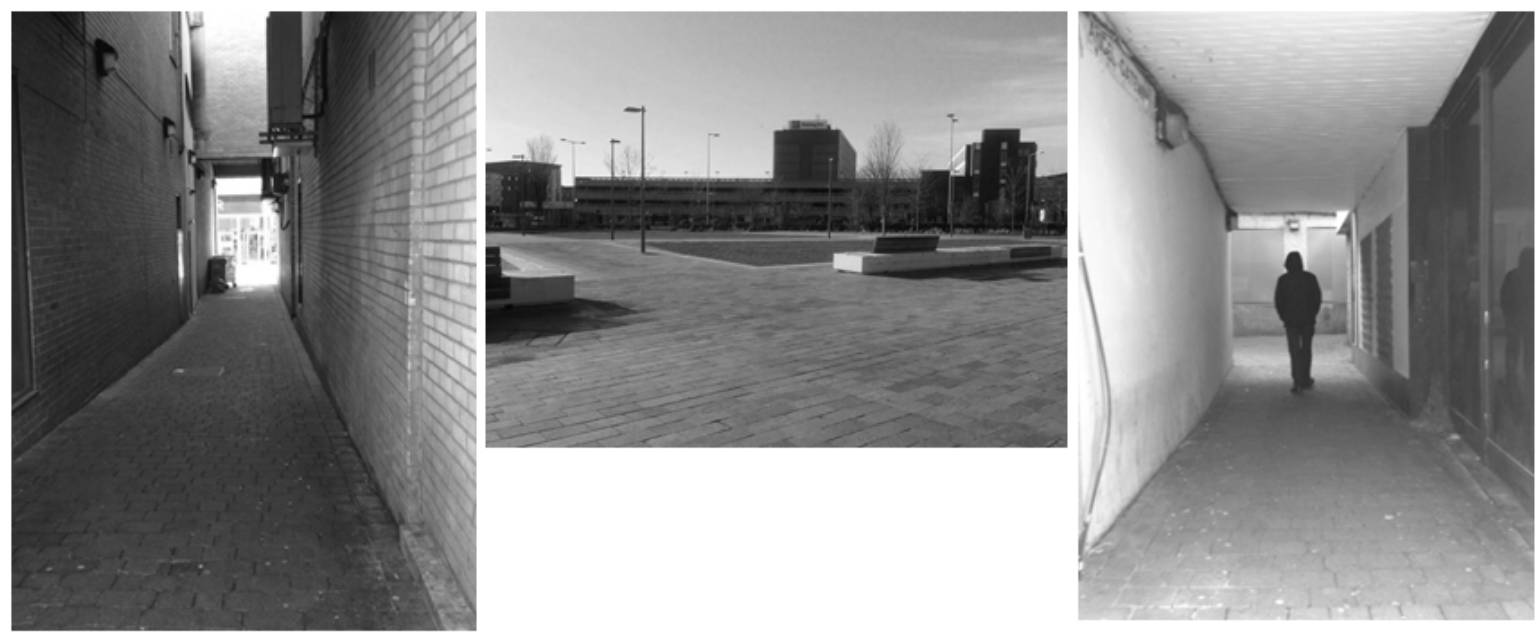

777 Figure 1. Examples of the images (Study 1) and key points (Study 2), including an alleyway (i.e., a crime hotspot; far left) an open area (i.e., a safespot; middle) and a lone shadowy male (right). 

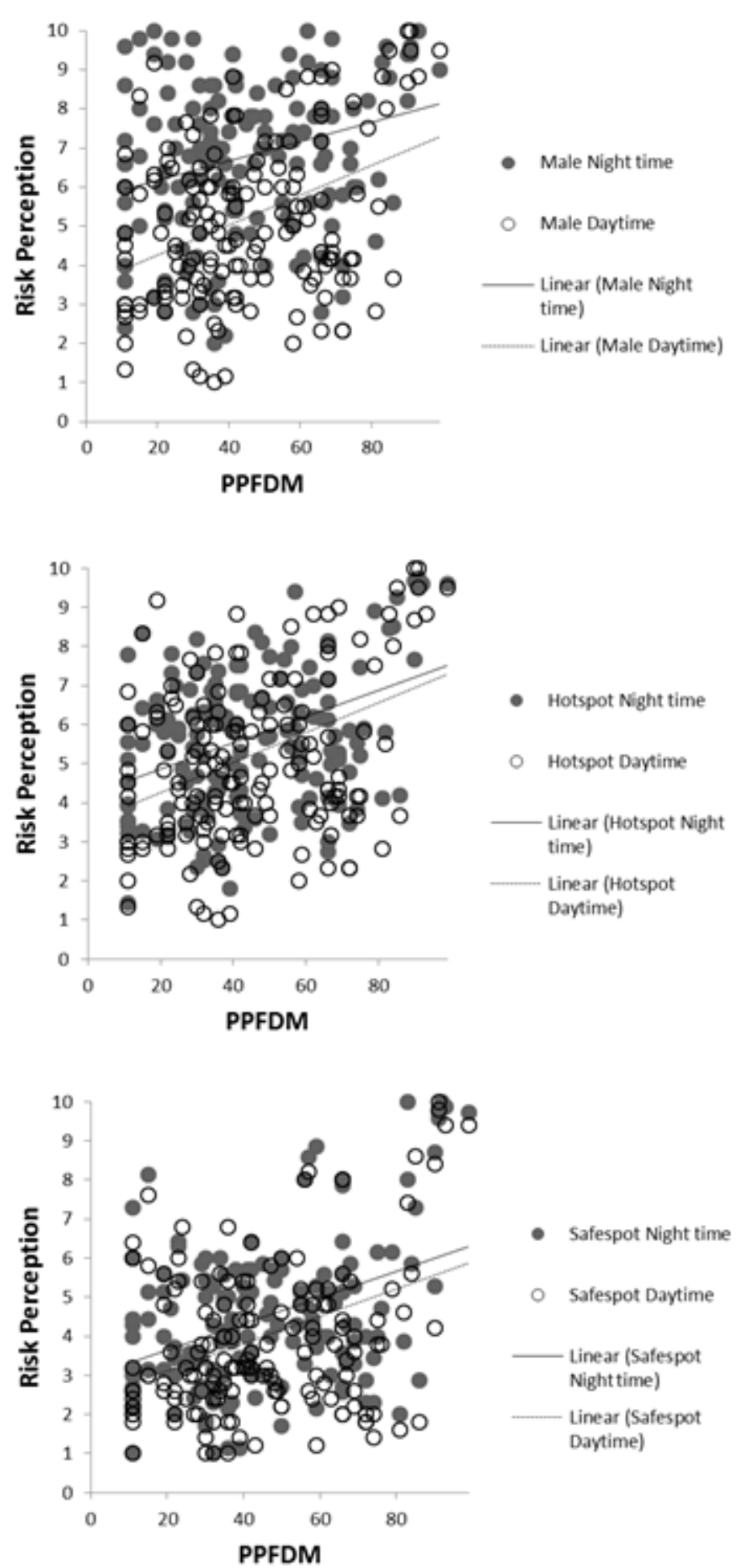

781

782

Figure 2. The relationship between risk perception and PPFDM across situations, with the top panel

783 for the male images, the middle panel for the hotspot images, and the bottom panel for the safespot

784 images. Closed circles denote image ratings for the night time condition, and open circles denote

785 image ratings for the daytime condition. 

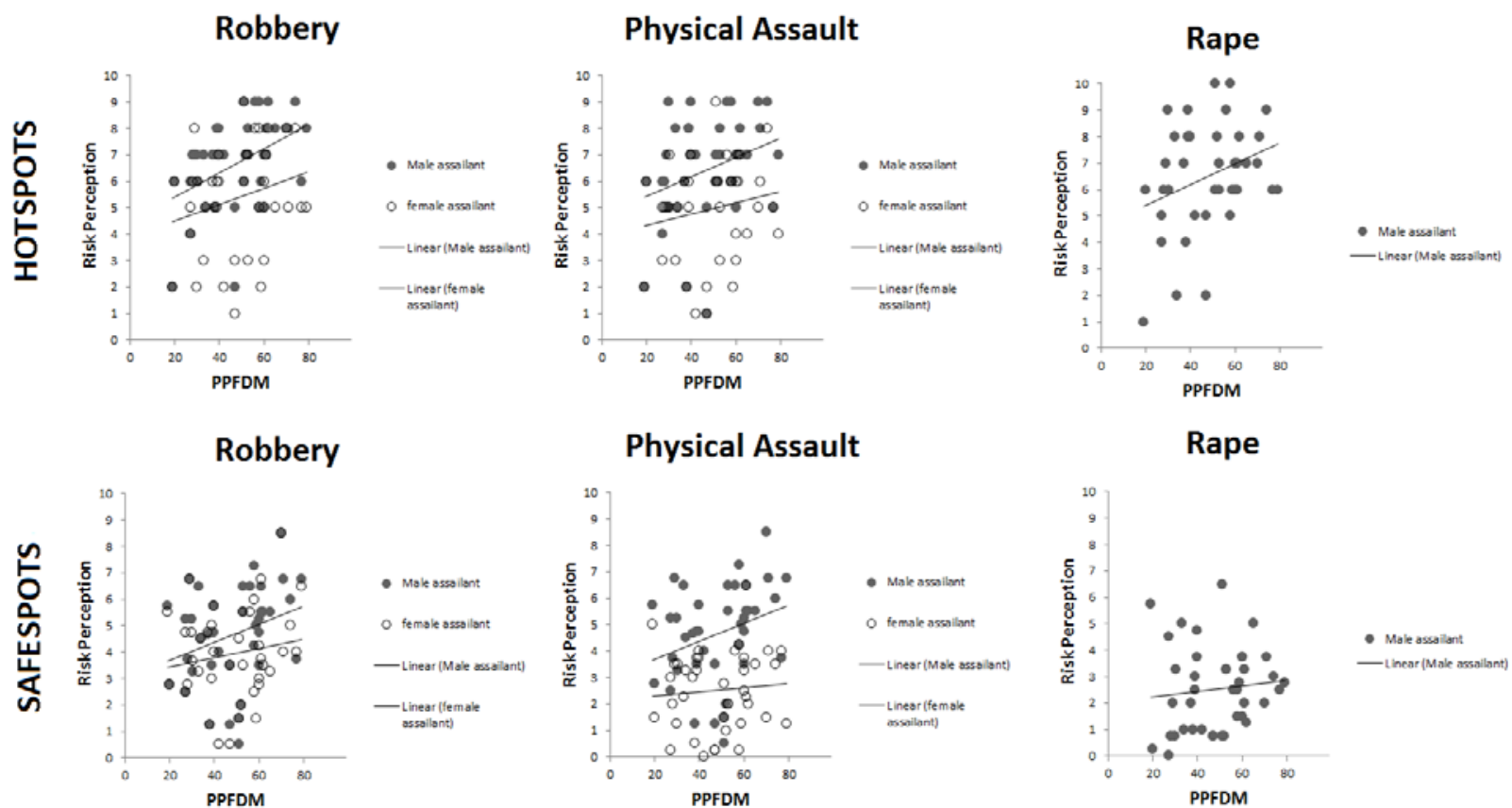

Physical Assault

Rape
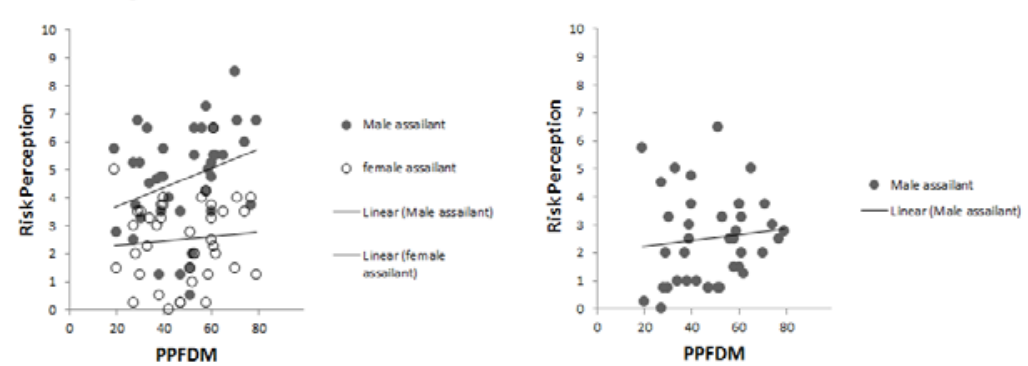

Figure 3. Preference for formidable mates and perceived personal risk of crime (robbery, physical

assault, and rape) by assailant gender and location. The data for crime hotspots are plotted in the top panel, and the data for safespots are plotted in the bottom panel. 
Hotspot

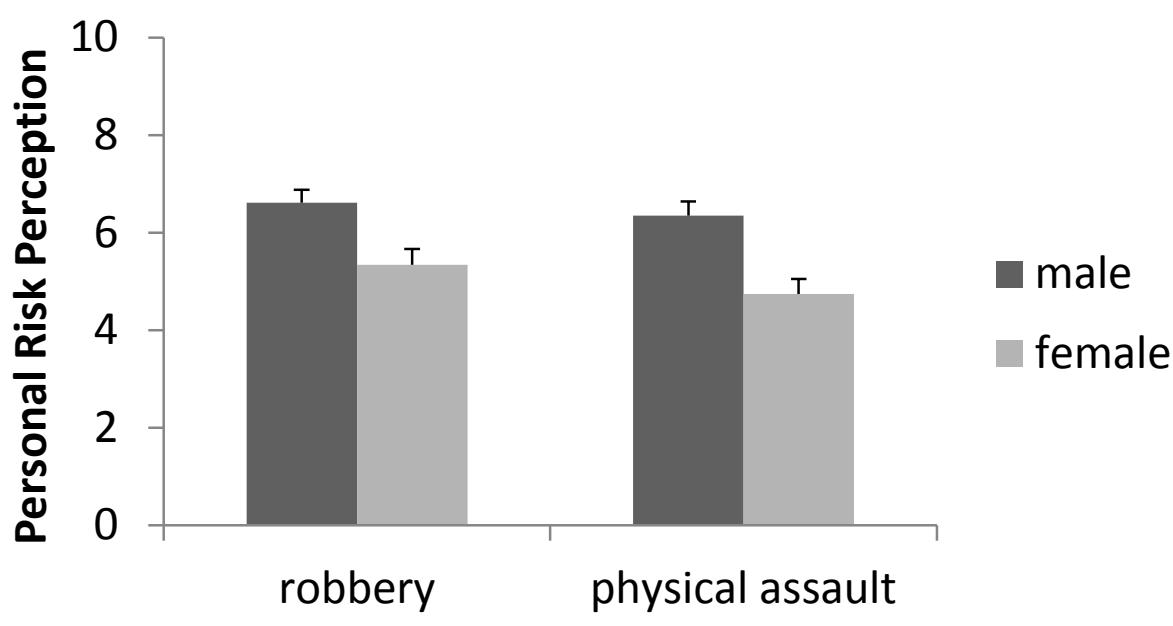

792

Safespot

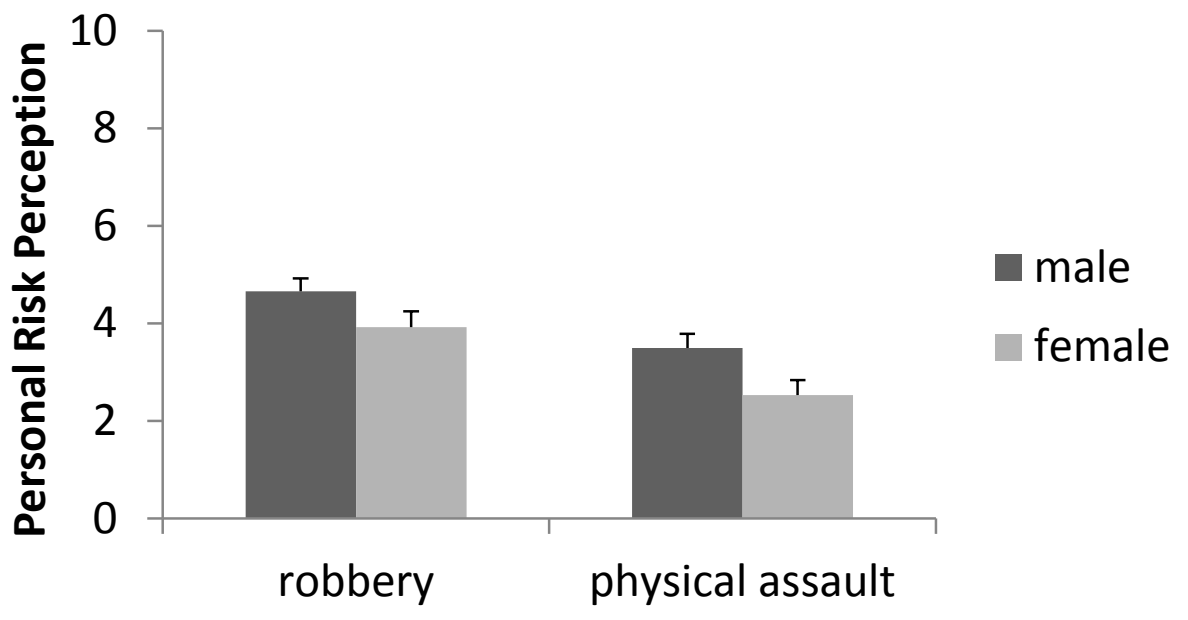

793

794

Figure 4. Mean personal risk perception (+1SEM) by location, crime type, and assailant gender.

795

796

797

798 